\title{
Comparative effects of concept mapping and cooperative learning strategies on senior secondary school students' achievement in mathematics-trigonometry in Kano state, Nigeria
}

\author{
Thomas D. Bot ${ }^{1}$, John E. Eze ${ }^{2}$ \\ ${ }^{1}$ Department of Science \& Technology Education, Faculty of Education, University of Jos, Plateau State, Nigeria \\ 2, Department of Mathematics, Federal College of Education (Technical), Bichi, Kano state, Nigeria \\ For correspondence: tomasbot@gmail.com
}

\begin{abstract}
This article presents the findings from an experimental study on the effectiveness of concept mapping and cooperative learning strategies on SSII students' achievement in trigonometry in mathematics. The research design used in conducting the study was quasi-experimental pre-test and post-test non-equivalent control group. The sample consisted of 210 (110 males \& 100 females) SSII students from three senior secondary schools in Kano metropolis, Kano state, Nigeria. The main objectives of the study were to find out whether a significant mean difference exists in students' achievement in trigonometry when taught with concept mapping and cooperative learning strategies, and find out the effects of the two strategies on achievement based on gender. Data was collected using researchers developed achievement test in trigonometry tagged PRE-TAT \& POST-TAT with a reliability coefficient of 0.75 . Data analysis was done using descriptive statistics and Analysis of Covariance (ANCOVA). The findings from the study among other things showed that the students taught using concept mapping performed better than those taught using cooperative learning strategy and both the two strategies were significantly better than the use of conventional teaching methods. The male students taught with concept mapping performed significantly better than female students. Also, the findings revealed the existence of gender differences in achievement of the students taught using cooperative learning strategy as against the use of conventional methods where it was discovered that female students performed significantly better than male students. It was recommended among other things that curriculum planners should incorporate concept mapping and cooperative learning strategies in mathematics curriculum guidelines towards the enhancement of achievement of senior secondary school students in mathematics.
\end{abstract}

Keywords: Concept mapping, Cooperative learning, Trigonometry, Achievement, Gender, Mathematics.

\section{Introduction}

The importance of mathematics especially in the development of science and technology has been well recognized and accepted worldwide (Eze, 1997; Bajah, 2000; Eguavon, 2002). According to Ukeje (1997), the increasing importance and attention given to mathematics stem from the fact that without mathematics, there will be no science, without science, there will be no modern technology and without modern technology, there will be no modern society. In other words, mathematics is the precursor, cornerstone and the queen of science and technology as well as an indispensable single factor required in modern societal development.

However, there is the need for students in the secondary school especially in Nigeria to improve on their performance in mathematics since according to Galadima (1998) the performance has continued to deteriorate year after year. Adeniyi (1988) and Galadima and Yusha'u (2007) pointed out some of the reasons why secondary school students perform poorly in mathematics to include the use of poor quality instructional methods, techniques and strategies, negative attitudes, shortage of qualified mathematics teachers and poor learning environment. These problems most especially the use of poor 
quality instructional methods, techniques and strategies by mathematics teachers can be minimized to a large extent if enough qualified mathematics teachers are employed and are well equipped with various teaching methods, techniques or strategies like concept mapping technique and cooperative learning strategy through proper on-the-job-training. This is because any form of improvement in the performance of students in mathematics at any given level of education is dependent on the type of teaching methods employed by classroom teachers. Also, the use of teaching methods especially innovative ones, have the capacity to help secondary school students learn difficult concepts in novel ways thereby increasing their performance and interest in mathematics. Consequently, there is need for an investigation into the effectiveness of some of the new or innovative instructional methods, techniques and strategies particularly the application of concept mapping and cooperative learning in mathematics instruction in the secondary school in Nigeria. This is, therefore, the main focus of this study.

Concept map has been described as a schematic device for representing a set of concept meanings embedded in a framework of propositions (Novak \& Godwin, 1984). Okebukola (1999) defined concept map to mean perceived regularity in events or objects designated by arbitrary labels. Concept mapping as an instructional strategy refers to the process of teaching and learning whereby concepts to be learned including their meanings are planned and broken down using diagrams or maps. This enables teachers to select, organize and represent subject matter or contents concisely. It helps teachers and students to observe, infer, classify and construct meanings from concepts in a hierarchy easily and meaningfully (Inomiesa \& Unuero, 2003). Also, it helps students to visualize the relationships between various concepts and their meanings and how the concepts are exemplified in theory and practice.

Some researchers have evaluated the effectiveness of using concept mapping instructional strategy in improving achievement of secondary school students in different subject areas. The findings generally tend to favour students who received instructions through the use of concept mapping as opposed to the use of conventional teaching methods. For instance, Ajaja (2011) conducted a study on the effect of concept mapping as a study skill on students' achievement in biology. The findings from the study revealed a significant increase in average scores of the students who were taught concept mapping as a study skill considered to be useful element in understanding and achieving better results in biology. Ezeugo and Agwagah (2000) investigated the effect of concept mapping on students' achievement in algebra in mathematics in the secondary school. It was discovered that gender is a significant determining factor that affects students' achievement in learning algebra in the secondary school. Consequently, it was discovered that male students achieved significantly better results than female students in algebra after applying concept mapping as a treatment. Similarly, Candan (2006) investigated the effect of concept mapping on students' understanding of the concepts of force and motion in physics. The findings from the study showed that although gender was not a significant determining factor in students' achievement in force and motion, there was a significant difference between the mean scores of the students that were exposed to concept mapping instructional strategy and those who were not exposed to it.

Cooperative learning in mathematics instruction has been described as the process which students are made to sit and work together to accomplish a common goal under the guidance of their teacher (Eze, 2009). This strategy has many features including the fact that it involves having students work in teams or groups on problems or projects under conditions that assures both positive interdependence and individual accountability (Felder \& Brent, 2001), the success of one or a number of student helps others to be successful too (Slavin, 1987), and it promotes the principles of shared leadership and responsibility (Penick \& Alan, 1995). These features, no doubt, suggest that cooperative learning is an important teaching and learning strategy. This is further confirmed by many researchers regarding its application in mathematics instruction in the secondary school. For instance, Johnson and Johnson 
(1987) pointed out that students in cooperative learning groups taught together usually gain a sense of positive interdependence and a sink or swim together perception.

According to Totten, Sills and Russ (1991), shared learning being one of the main principles of cooperative learning gives students the opportunity to engage in discussion, take responsibility for their own learning and thus become critical thinkers. Also, cooperative learning assists students to do it by themselves as opposed to watching the teacher doing it and the students accepting every concept that is taught hook-line-and-sinker. According to Eze (2007), this is one of the cardinal principles required in problem solving in mathematics since mathematics is learned by doing and solving problems is supposed to help students to learn formulas and techniques which are useful in improving problem solving prowess and students are also supposed to use the tools in solving practical problems independently or otherwise. Clearly, the concept and process of learning by doing is one of the reasons why cooperative learning is important and it is inevitable in addressing the myriad of problems confronting the dissemination of mathematics in classrooms in the primary and secondary schools in Nigeria and beyond.

Besides advantages, the effectiveness of cooperative learning like concept mapping has been demonstrated in a number of documented research studies. In a meta-analysis of 63 studies on the effects of cooperative learning strategy on the achievement of students in different school subjects including mathematics, Slavin (1987) discovered that in $57 \%$ of the studies, there was a significant mean difference in the achievement of the students exposed to the method while there was no such significant difference in $41 \%$ of the studies but there was improvement in the overall achievement of the students. In a recent study, Eniayeju (2010) found out that cooperative learning strategy has a significant mean differential effect on the performance of secondary school students in mathematics based on gender with the result that girls in the cooperative learning group performed significantly better than boys in the same group.

Based on the need to improve the achievement of secondary school students in mathematics especially in trigonometry in Nigeria, it is important to find out the extent to which concept mapping versus cooperative learning strategies will assist students to learn and achieve better learning outcomes. Trigonometry is one of the branches of general mathematics in the secondary school in Nigeria that deals with the study of triangles and the relationships that exist between the sides and angles of the triangles. The knowledge of trigonometry is important because it is useful in studying different courses in tertiary institutions like engineering, physics, architecture and survey. Also, the knowledge is important because it is said to unite geometry and algebra which are studied by all students in the secondary school in Nigeria (Lassa, 2012). It is due to the importance of the knowledge of trigonometry in training students that the current reformed secondary school mathematics curriculum in Nigeria contains a huge number of trigonometry concepts and also about $25 \%$ of the objectives and essay questions that the West African Examinations Council (WAEC) and the National Examinations Council (NECO) usually set are derived from trigonometry. Unfortunately, most candidates for these examinations perform poorly in this important aspect of mathematics because they find it difficult to understand and apply the knowledge.

Some of the difficulties that students often experience leading to poor understanding and application of trigonometry in mathematics in the secondary school in Nigeria include inability to represent problems diagrammatically, poor knowledge of trigonometric ratios and identities dealing with sine, cosine and tangent, and inability to understand and solve simple trigonometry equations like $\tan (\varnothing+$ $\left.25^{\circ}\right)=5.145$ and $\tan \theta=\sqrt{3} / 2$ (Chief Examiners' Reports for WAEC, 2008; 2009). Consequently, students need good couching in trigonometry in the secondary school in Nigeria in order for them to develop a good foundation and to improve their overall performance in mathematics since the knowledge is very important as it constitutes a major part of the general mathematics that they need to study. 
Female students in particular need proper grooming in this important branch of mathematics so as to help them to improve their overall performance in mathematics since they are said to trail behind male students (Muscio, 1993; Moses, 2004; Adewale, 2005).

\section{Statement of the Problem}

Many students in the secondary school in Nigeria often experience difficulties in understanding, comprehending, assimilating and applying mathematics concepts in solving practical problems most especially those dealing with trigonometry. This leads many of the students to score low and discouraging marks in their examinations in mathematics especially in WAEC and NECO conducted examinations. Since the knowledge of mathematics particularly trigonometry is very important to the extent that without it, there can be no meaningful development in science and technology, it therefore, behoves on mathematics teachers in Nigeria to continue to search for new and relevant teaching and learning strategies that could help their students to learn and achieve better results and to develop genuine interest in the subject. Learning of mathematics with understanding is very important because it will help disabuse the perception students have that mathematics is difficult and abstract as well as enable them to reduce rote memorization to the barest minimum. Once these impeding factors are contained, students are most likely to understand as they are most likely to achieve huge success in their achievement in mathematics. The problem of this study thus is to examine the extent which the use of concept mapping and cooperative learning strategies will assist secondary school students in Nigeria to understand or assimilate and apply the knowledge of trigonometry concepts in mathematics and also test and ascertain their level of achievement in the subject. In specific terms, the study is designed to achieve the following objectives: to determine the effects of concept mapping and cooperative learning strategies on the achievement of SSII students in trigonometry; find out whether there is a significant mean difference in achievement of SSII students in trigonometry after being exposed to concept mapping and cooperative learning strategies; find out whether the achievement of SSII students in trigonometry will vary based on gender when the two strategies are employed; and find out the interaction effects of the two strategies on achievement of SSII students in trigonometry.

To achieve the objectives of the study, two research questions were raised and three hypotheses were formulated and tested at 0.05 level of significance. These are as follows: What are the main effects of concept mapping and cooperative learning instructional strategies on achievement of SSII students in trigonometry? What is the difference between the mean achievement scores of SSII male and female students when taught using concept mapping and cooperative learning instructional strategies in trigonometry? There is no significant mean difference in the achievement scores of the treatment and control groups; the mean difference in achievement scores of students in the treatment and control groups will not vary significantly based on their gender; and there is no significant mean difference in the interaction effects of the treatments on the achievement of the students based on gender.

\section{Method}

Research design, sample and sampling techniques: The study adopted a pre-test and post-test nonequivalent control group quasi-experimental research design because the students were taught in their intact classes without randomization. The study sample was made of 210 SSII male and female students from three randomly selected secondary schools in Kano metropolis, Kano state in Nigeria. Purposive sampling technique was used in selecting (1) the three senior secondary schools and (2) two streams from each of the selected three senior secondary schools while simple random sampling technique was employed to assign each stream as either experimental or control group based on the intact classroom arrangement of the students. 
Instrument: The instrument used for data collection was a Pre-Trigonometry Achievement Test (PRETAT) which also served as Post-Trigonometry Achievement Test (POST-TAT). It was made of 10 essay questions in trigonometry dealing with the concepts of sine and cosine rules and their applications in practical life. The instrument was developed by the researchers and validated by mathematics education and test and measurement experts. Thereafter, it was pilot-tested where the coefficient of internal consistency was calculated through the use of SPSS (Cronbach Alpha Coefficient) yielding 0.78 .

Procedure: The experiment started with initial pretesting of the two experimental groups and the control group with the PRE-TAT to establish a statistical baseline in their entry behaviours. In administering the treatment properly through trained research assistants, the experimental group one received teaching using concept mapping and experimental group two received teaching through cooperative learning strategy. The units of concepts in trigonometry in mathematics contained in the treatment package for the two experimental groups were based on proving sine and cosine rules, calculations of the lengths, sides and angles of various triangles using sine and cosine rules and the application of sine and cosine rules in calculating practical problems involving bearing; and angles of elevation and depression. The control group on the other hand received the normal lessons in trigonometry with similar topics as the experimental groups for the length of the study lasting four weeks. After the period of the experiment, the three groups were all post-tested using the POST-TAT. Materials and Methods: The teaching and learning materials; and the various methods, techniques and strategies used in aiding the students in the experimental groups one and two include discussion, grouping, demonstration, drawing, construction, sketching, illustrations, flash cards, concept maps, measuring tapes, meter rule, protractors and models of different triangles including right-angled triangles. Others include cardboard papers, scissors, markers, pair of compasses, activity sheets or workbooks and so on.

Data Analysis: Data collected from the study were analyzed through the use of descriptive and inferential statistics namely means, standard deviations, ANOVA and ANCOVA based on the research questions and hypotheses raised in the study.The paper should be prepared in English according to the written and/or visual guidelines shown here in this template. You may either format your own document, or copy and paste your text into appropriate places in this template, making sure that you maintain the template's original format. You should delete all the coloured instructional text that appears in brackets throughout the document.

\section{Results}

Table 1. Nature of Means and Standard Deviations in Achievement Scores in PRE-TAT and POSTTAT of the Experimental and Control Groups

\begin{tabular}{llllllll}
\hline Group & \multirow{2}{*}{ Method } & \multicolumn{2}{l}{ PRE-TAT } & \multicolumn{2}{l}{ POST-TAT } & N & Adj. Mean \\
& & Mean & SD & Mean & SD & & Square \\
\hline Cont & Trad & 14.12 & 11.11 & 22.71 & 10.40 & 70 & 22.21 \\
Exp1 & Conc Map & 13.40 & 7.92 & 29.75 & 9.70 & 70 & 30.28 \\
Exp2 & Coop learning & 17.76 & 7.18 & 29.98 & 10.37 & 70 & 30.02 \\
\hline
\end{tabular}

Cont=Control, Exp=Experimental, Trad=Traditional, Conc=Concept, $\mathrm{Coop}=$ Cooperative

Table 1 shows that the subjects in experimental group one gained from the use of the concept mapping with a post-test mean score of 29.75 compared with their pretest mean score of 13.40 which is lower. Experimental group two also gained from the use of cooperative learning strategy with a post-test mean score of 29.98 compared with their lower pretest mean score of 17.76 . The statistics also reveal that both the experimental groups gained better than the control group with a post-test mean score of 22.71 . 
Table 2. Summary of ANCOVA Calculations on Achievement of the Control and Experimental Groups on Trigonometry Achievement Test

\begin{tabular}{cccccc}
\hline $\begin{array}{c}\text { Sources of } \\
\text { Variation }\end{array}$ & $\begin{array}{c}\text { Type111 Sum of } \\
\text { Squares }\end{array}$ & Df & $\begin{array}{c}\text { Mean } \\
\text { Squares }\end{array}$ & F-cal. & Sig. \\
\hline Corrected Model & $24260.849^{a}$ & 2 & 12130.424 & 554.816 & 0.000 \\
Intercept & 179944.176 & 1 & 17944.176 & 820.732 & 0.000 \\
Pre-TAT & 14128.011 & 1 & 14128.011 & 646.181 & 0.000 \\
Method & 12813.223 & 2 & 12813.223 & 586.046 & 0.000 \\
Error & 5837.651 & 207 & 21.864 & & \\
Total & 212618.500 & 210 & & & \\
Corrected total & 30098.500 & 209 & & & \\
\hline
\end{tabular}

R Square $=0.28($ Adjusted $\mathrm{R}$ Square $=0.199)$

Table 2 shows that, based on the main effect of teaching method $(F 2,207)=586.046$, p-value of 0.000 is less than $\alpha=0.05$, there is a significant mean difference between the post-test achievement scores of the two experimental groups and the control group. The use of methods of teaching, that is, traditional method, concept mapping and cooperative learning strategies thus helped the experimental and control groups significantly. The actual source of the significance of the mean difference was determined by Scheffe's Post-hoc analysis in Table 3.

Table 3. Scheffe's Post-hoc Test for Significance of the Difference between the Post-test Mean Scores of the Three Groups Based on Methods of Teaching Trigonometry

\begin{tabular}{lllll}
\hline Strategy & Strategy & Post-test Score Difference & Standard Error & Sig. \\
\hline Coop Learning & Conc Mapping & $2.83^{*}$ & 0.864 & 0.012 \\
& Conv & $3.57^{*}$ & 0.864 & 0.001 \\
Conc Mapping & Coop Learning & $2.83^{*}$ & 0.864 & 0.012 \\
& Conv & $6.56^{*}$ & 0.864 & 0.000 \\
Conv & Coop Learning & $-3.57^{*}$ & 0.864 & 0.001 \\
& Conc Mapping & $-6.56^{*}$ & 0.864 & 0.000 \\
\hline
\end{tabular}

Coop $=$ Cooperative, Conc $=$ concept, Conv $=$ Conventional

From Table 3, the post-test achievement mean score based on the use of concept mapping and cooperative learning strategies is 2.83 with a $\mathrm{p}$-value of 0.012 is less than $\alpha=0.05$. This means there is a significant mean difference in the application of the two strategies. Also, between cooperative learning and other strategies, that is, concept mapping and conventional method, it revealed that there exists a significant mean difference since both $p$-value $=0.012$ and $p$-value $=0.001$ are each less than $\alpha=0.05$. Similarly, the post-test mean scores of 2.83 and 6.56 revealed a significant mean difference in achievement in trigonometry in the use of concept mapping and cooperative learning strategies and conventional teaching method since the p-values of 0.012 and 0.000 are each less than $\alpha=0.05$. In the same vein, for the post-test mean score difference of -3.57 and -6.56 in the use of conventional method and cooperative learning, the concept mapping strategy score difference resulted in $p$-value $=0.001$ and $p$-value $=0.000$ each of which is less than $\alpha=0.05$. Therefore, the overall statistics from Table 3 revealed that the use of concept mapping instructional strategy resulted in a significant mean difference in the achievement of the subjects in trigonometry. This is followed by the use of cooperative learning strategy and lastly the use of conventional teaching methods.

Table 4. Summary of Mean Achievement Scores and Standard Deviation of Male and Female Students Taught Using Concept Mapping Instructional Strategy

\begin{tabular}{llllll}
\hline Gender & Test & N & Mean & SD & Mean Gain \\
\hline Male & Pre-test & 38 & 13.10 & 2.94 & \\
& Post-test & 38 & 13.74 & 1.89 & 0.74 \\
\hline
\end{tabular}




\begin{tabular}{llllll}
\hline Female & Pre-test & 32 & 13.19 & 1.73 & \\
& Post-test & 32 & 13.70 & 1.54 & 0.51 \\
\hline
\end{tabular}

Table 4 shows that the post-test achievement mean score of the male students exposed to concept mapping was 13.74 while that of female students was 13.70 . The mean gain for the male students (0.74) was better than the mean gain for the female students (0.51). Table 5 explains the statistical significance of the mean gain between the male and female students.

Table 5: Summary of ANCOVA Calculations/Statistics on the Pretest and Post-Test Scores of the Male and Female Students Exposed to Concept Mapping Instructional Strategy

\begin{tabular}{|c|c|c|c|c|c|}
\hline $\begin{array}{l}\text { Source of } \\
\text { Variation }\end{array}$ & $\begin{array}{l}\text { Sum of } \\
\text { Squares }\end{array}$ & Df & $\begin{array}{l}\text { Mean } \\
\text { Square }\end{array}$ & F-cal & Sig. \\
\hline Corrected Model & $80.085^{a}$ & 2 & 40.042 & 7.912 & 0.001 \\
\hline Intercept & 224.815 & 1 & 224.815 & 44.421 & 0.000 \\
\hline Pre-test & 12.845 & 1 & 12.845 & 2.538 & 0.115 \\
\hline Gender & 43.542 & 1 & 43.542 & 8.702 & 0.003 \\
\hline Error & 490.915 & 67 & 5.042 & & \\
\hline Total & 17212.000 & 70 & & & \\
\hline Corrected Total & 571.000 & 69 & & & \\
\hline
\end{tabular}

Table 5 shows that the $\mathrm{p}$-value of 0.003 for gender is less than $\alpha=0.05$. This means that the difference in the achievement mean scores of the students in trigonometry from the use of concept mapping strategy based on gender (males and females) is statistically significant.

Table 6: Mean Achievement Scores and Standard Deviation of Male and Female Students Exposed to

\begin{tabular}{llllll}
\multicolumn{5}{c}{ Cooperative Learning Instructional Strategy } \\
\hline Gender & Test & N & Mean & SD & Mean Gain \\
\hline Male & Pre-test & 37 & 16.7 & 8.58 & \\
& Post-test & 37 & 20.5 & 13.2 & 3.80 \\
Female & Pre-test & 33 & 17.1 & 7.0 & \\
& Post-test & 33 & 22.3 & 14.5 & 5.20 \\
\hline
\end{tabular}

From Table 6, the post-test mean achievement scores of the male students exposed to cooperative learning strategy was 20.5 while that of the female students was 23.3. The mean gain in the achievement of the female students (5.20) is higher than that of the male students (3.80). The statistical significance of the mean gain is explained in Table 7.

Table 7: Summary of ANCOVA Calculations/Statistics on the Post-Test Scores of Male and Female Students Exposed to Cooperative Learning Strategy

\begin{tabular}{llllll}
\hline $\begin{array}{l}\text { Source of } \\
\text { Variation }\end{array}$ & $\begin{array}{l}\text { Sum of } \\
\text { Squares }\end{array}$ & Df & $\begin{array}{l}\text { Mean } \\
\text { Square }\end{array}$ & F-cal & Sig. \\
\hline Corrected Model & 1646.272 & 2 & 823.136 & 29.305 & 0.000 \\
Intercept & 4519.557 & 1 & 4519.557 & 160.902 & 0.000 \\
Pre-test & 1625.372 & 1 & 1625.372 & 57.865 & 0.000 \\
Gender & 0.551 & 1 & 0.551 & 0.20 & 0.789 \\
Error & 1601.052 & 67 & 28.089 & & \\
Total & 2567.00 & 70 & & & \\
Corrected Total & 3247.33 & 69 & & & \\
\hline$=0.408$ (Adjusted R Squared $=0.390)$ & & &
\end{tabular}

R Squared $=0.408$ (Adjusted R Squared $=0.390$ ) 
From Table 7, the p-value of 0.789 based on gender (males and females) in achievement in trigonometry from the use of cooperative learning strategy is strictly greater than $\alpha=0.05$. This shows that there is no statistical significant mean difference in the achievement of the students in trigonometry based on gender when taught using cooperative learning strategy.

Table 8. Summary of ANCOVA Calculations/Statistics on the Interaction Effect of Concept Mapping Strategy on Achievement of Students in Trigonometry

\begin{tabular}{llllll}
\hline $\begin{array}{l}\text { Source of } \\
\text { Variation }\end{array}$ & $\begin{array}{l}\text { Sum of } \\
\text { Squares }\end{array}$ & Df & $\begin{array}{l}\text { Mean } \\
\text { Square }\end{array}$ & F-cal & Sig. \\
\hline Corrected Model & $80.085^{\mathrm{a}}$ & 4 & 40.042 & 7.912 & 0.001 \\
Intercept & 224.815 & 1 & 224.815 & 44.421 & 0.000 \\
Pre-test & 12.845 & 1 & 12.845 & 2.538 & 0.115 \\
Gender & 43.542 & 1 & 43.542 & 8.702 & 0.003 \\
Method & 256.601 & 1 & 256.601 & 38.052 & 0.000 \\
Gender *Method & 126.442 & 1 & 126.442 & 23.456 & 0.099 \\
& & & & & \\
Error & 490.915 & 65 & 5.042 & & \\
Total & 17212.000 & 70 & & & \\
Corrected Total & 863.000 & 69 & & & \\
\hline
\end{tabular}

$\mathrm{R}$ Squared $=0.140$ (Adjusted R Squared $=0.123$ )

Table 8 shows the summary of ANCOVA statistics on the post-test scores of male and female students exposed to concept mapping strategy and the interaction effect. Although based on gender, the pvalue of 0.003 obtained is less than $\alpha=0.05$ meaning that there exists a significant difference in the mean achievement scores of the male and female students in favor of the male students but based on the p-value of 0.099 being strictly less than $\alpha=0.05, F(1,65)=5.042$, gender does not significantly interact with method to influence the students' mean achievement scores in trigonometry when taught using concept mapping. The statistics however indicated that method of teaching has a significant effect on the groups since $\mathrm{F}(1,65)=38.052$, and $\mathrm{p}$-value of 0.000 is less than $\alpha=0.05$.

Table 9. Summary of ANCOVA Calculations/Statistics on the Interaction Effect of Cooperative Learning Strategy on Students Achievement in Trigonometry

\begin{tabular}{llllll}
\hline $\begin{array}{l}\text { Source of } \\
\text { Variation }\end{array}$ & $\begin{array}{l}\text { Sum of } \\
\text { Squares }\end{array}$ & Df & $\begin{array}{l}\text { Mean } \\
\text { Square }\end{array}$ & F-cal & Sig. \\
\hline Corrected Model & 1646.272 & 2 & 823.136 & 29.305 & 0.000 \\
Intercept & 4519.557 & 1 & 4519.557 & 160.902 & 0.000 \\
Pre-test & 1625.372 & 1 & 1625.372 & 57.865 & 0.000 \\
Gender & 120.551 & 1 & 120.551 & 2.204 & 0.789 \\
Method & 246.031 & 1 & 246.031 & 79.072 & .000 \\
Gender*Method & 97.663 & 1 & 97.664 & 6.588 & .011 \\
& & & & & \\
Error & 1601.052 & 65 & 37.089 & & \\
Total & 2567.00 & 70 & & & \\
Corrected Total & 3247.33 & 69 & & & \\
\hline$=0.408$ (Adjusted R Squared $=0.390)$ & & &
\end{tabular}

From Table 9, the p-value of 0.789 is greater than $\alpha=0.05$ indicating that there is no any significant mean difference in the achievement of male and female students when taught trigonometry using cooperative learning strategy but method of teaching has a significant effect on the main groups since $\mathrm{F}(1,65)=79.072$ and $\mathrm{p}$-value of 0.000 is less than $\alpha=0.05$. The ANCOVA statistics also indicated that there is a significant difference in the achievement of the students in the experimental and control 
groups and there is a significant interaction effect of group and method of teaching (cooperative learning strategy) regarding the achievement of students in trigonometry since $\mathrm{F}(1,65)=6.588$ and $\mathrm{p}$ value of 0.011 is strictly less than $\alpha=0.05$.

\section{Discussion}

In Nigeria and many other countries, the need for improving the achievement and overall performance of students in mathematics in the secondary school is not in doubt. This is because besides elevating the standard of performance of the students in mathematics generally and appreciating its role in building a complete human being, among other things, the knowledge is highly indispensable in producing a dynamic and progressive scientific and technological society. Therefore, any effort no matter how little that is put to emerge with new methods of teaching to promote effective and efficient dissemination of mathematical knowledge to students will be highly appreciated in the present circumstance. This study was thus conceived specifically to determine the extent which two innovative teaching strategies namely concept mapping and cooperative learning strategies can help mathematics teachers to achieve this objective. Based on this premise, the findings from this study have been discussed to examine the significance of the effects of the two teaching strategies against the use of conventional teaching methods.

From Tables 1 and 2, the findings from the study showed that the experimental groups benefited immensely from the study and performed better than the control group. Specifically, for the group taught concept mapping, the students performed (posttest mean score=29.75) almost equally with those in the cooperative learning group (posttest mean score $=29.98$ ) while the two experimental groups performed better than the control group (posttest mean score=22.71). However, based on the main effect of teaching method in which $\mathrm{F}(2,207)=586.046$ and p-value of 0.000 is less than $\alpha=0.05$, there is a significant mean difference between the posttest achievement scores of the experimental groups. This implies that the two innovative teaching strategies helped the students significantly. The actual source of the significance of the mean difference was determined by Scheffe's Post-hoc analysis in Table 3 in which it was found out that there is a significant mean difference in the application of the two innovative teaching strategies. These findings are consistent with Asan (2007), Ezeugo and Agwagah (2000) who discovered in their respective studies that concept mapping as a form of instructional strategy is not only effective in increasing students' achievement in mathematics, it also leads to a significant mean difference in the achievement of the students when compared with the use of regular, traditional or conventional teaching methods in the secondary school.

Also, from Tables 4 and 5, the findings from the study based on gender revealed that the male students exposed to concept mapping performed significantly better than female students since the mean gain for the male students (0.74) was better than the mean gain for the female students $(0.51)$ and the p-value of 0.003 for gender was less than $\alpha=0.05$. On the contrary, the findings of the study from Table 6 revealed that, on the average, the male students exposed to cooperative learning strategy with a mean score of 20.5 did not perform better than their female colleagues with a higher mean achievement score of 23.3. However, Table 7 revealed that even though the female students performed better than their male colleagues on the average, the difference was not statistically significant since the $\mathrm{p}$-value of 0.789 was strictly greater than $\alpha=0.05$. This invariably suggest that the performance of secondary school students in mathematics based on their gender is affected by the type of method of teaching employed by teachers in the classroom. Thus mathematics teachers need to take into consideration the type of teaching methods to use whenever they are to teach the subject to a mixed group of students.

Furthermore, the findings from the study based on the results in Tables 8 and 9 revealed that although there exists a significant mean difference in the achievement scores of the male and female students exposed to concept mapping ( $\mathrm{p}$-value $=0.099$ strictly less than $\alpha=0.05, \mathrm{~F}(1,65)=5.042$ ), gender 
does not have any significant interaction effect on the students' achievement scores in the trigonometry concepts taught. Also, the findings from the study revealed that even though there is no any statistical significant mean difference in the achievement of the male and female students exposed to cooperative learning strategy, the method of teaching generally tend to have a significant effect on the main learning groups since $\mathrm{F}(1,65)=79.072$ and $\mathrm{p}$-value of 0.000 was less than $\alpha=0.05$. In addition, the ANCOVA statistical analysis from the study (see Tables 8 and 9) revealed that there is a significant mean difference in the achievement of the students and also there is a significant interaction effect of group versus teaching method in the achievement of the students in trigonometry since $\mathrm{F}(1,65)=6.588$ and $\mathrm{p}$-value of 0.011 was strictly less than $\alpha=0.05$. On the whole, these findings concurred with Ezeugo and Agwagah (2000) and Ajaja (2011) who reported in their studies that male students achieved significantly better than female students when taught with concept mapping. The findings also concurred with Bot and Emefo (2014) who reported that innovative methods of teaching assist secondary school students irrespective of their gender to learn and achieve better learning outcomes in mathematics especially when problem solving method is employed.

\section{Conclusion}

Based on the findings from the study, it is thus concluded that the use of concept mapping and cooperative learning strategies assist students in the secondary school to learn, understand and achieve better results in trigonometry in mathematics than the use of traditional teaching methods. Whereas male students benefitted more from using concept mapping than their female colleagues, the female students on the other hand benefitted more than their male colleagues from using cooperative learning strategy in teaching trigonometry. Specifically, female students performed significantly better than male students in trigonometry when cooperative learning strategy is used while the reverse is the case when concept mapping is employed. Therefore, the use of cooperative learning strategy and concept mapping can be said to provide opportunity for students in the secondary school in Nigeria to acquire the knowledge of trigonometry in mathematics with success.

\section{Recommendations}

Based on the findings from the study, the following recommendations are made:

- $\quad$ Mathematics teachers especially those teaching the subject in the senior secondary schools in Nigeria should learn to incorporate the use of concept mapping and cooperative learning strategies. This will give their students the opportunity to engage in learning mathematics using innovative strategies and or techniques with high tendency to increase the performance and interest of the students in the subject. Also, it will help the teachers to reduce the rate which they depend on using traditional teaching methods in mathematics instruction which does not guarantee effective teaching and huge success for students.

- Curriculum planners for mathematics teaching and learning in the secondary school in Nigeria should incorporate concept mapping and cooperative learning instructional strategies in curriculum guidelines to help facilitate the achievement of intended learning outcomes.

One of the most important tools for effective mathematics instruction in the secondary school in Nigeria and elsewhere in the world is the mathematics textbook. Consequently, authors should develop mathematics textbooks that contain the use of different approaches including concept mapping and cooperative strategies. This will help to provide variety in terms of pedagogy in mathematics instruction in the secondary school.

The government at various levels (that is local, state and federal) and associations like the Mathematical Association of Nigeria (MAN) should organize special seminars, workshops and symposia for mathematics teachers and students in the secondary school in Nigeria on regular basis on the use of instructional models and methods. This will give opportunity for the teachers in particular to learn new techniques and strategies of teaching mathematics 
including concept mapping and cooperative learning towards enhancing the overall performance of their students in mathematics.

- $\quad$ There should be further research to examine the relative effectiveness of using the two innovative teaching strategies i.e. concept mapping and cooperative learning on the achievement and interest of students in mathematics in the secondary school in Nigeria. Besides interest, the relative effectiveness of the two strategies should be examined also on important research variables that help to determine the success of students in mathematics like ability, school type and level of study.

\section{References}

Adewale, A. O. (2005). Investigation of varieties in achievement in mathematics across gender in FCT Abuja. Unpublished M.Ed. Thesis, University of Jos.

Adeniyi, N. E. (1988). Mathematics in secondary schools. Journal of the Mathematical Association of Nigeria, 18 (1), 89-106.

Ajaja, O. P. (2011). Concept mapping as a study skill: Effects on students' achievement in biology. International Journal of Education Science, 3 (1), 49-57.

Asan, A. (2007). Concept mapping in science class. A case study of fifth-grade students. Educational Technology and Society, 10 (2), 186-195.

Bajah, S. T. (2000). Emerging global issues in education. A lead paper presented at the National Conference on Curriculum Innovation in the $21^{\text {st }}$ century held at Abuja from August 21st-26th.

Bot, T. D. \& Emefo, C. N. (2014). Effects of cooperative learning strategy on achievement of male and female students in algebra in Bichi Local Government Area of Kano state. International Journal of Research in Science, Technology and Mathematics Education, 2 (2), 86-98.

Candan, A. (2006). The effect of concept mapping on primary school students' understanding of the concepts of force and motion. Journal of Turkish Science Education, 3 (1), 66-75.

Eguavon, O. J. (2002). Mathematics, the heartbeat of information technology: Implication for secondary education. Journal of Mathematical Association of Nigeria, 27 (1), 10-112.

Eniayeju, A. A. (2010). Effects of cooperative learning strategy on the achievement of primary six pupils in mathematics. Journal of Mathematical Association of Nigeria, 35 (1), 1-9.

Ezeugo, N. C. \& Agwagah, U. N. V. (2000). Effects of concepts mapping on students' achievement in algebra: Implications for secondary mathematics education in the $21^{\text {st }}$ century. Journal of Mathematical Association of Nigeria, 25 (1), 1-12.

Eze, J. E. (1997). The relevance of mathematics to science and technology. Bichi Journal of Education, 2 (1), 82-88.

Eze, J. E. (2007). Active learning techniques in science and mathematics classroom: The role of the teacher. Knowledge Review, 14 (2), 82-88.

Eze, J. E. (2009). Effective delivery of mathematics instruction through cooperative learning: Implications for sustainable national development. The Nigerian Journal of Educational Review, 8 (9), 204-210.

Felder, R. M. \& Brent, R. (2001). Effective strategies for cooperative learning. Retrieved on 06/12/2014 from http://www,ncsu.edu/felder_public/cooperative-learning html.

Johnson, D. W \& Johnson, R. T. (1987). Learning together and alone: Cooperative, competitive and individualistic learning. Englewood Cliffs, NJ: Prentice Hall.

Inomiesa, E. A. \& Unuero, J. U. (2003). Concept mapping: A radical paradigm to guided discovery method in the teaching of science in Nigeria. Journal of Educational Research and Development, 2 (1), 111-119.

Galadima, I. (1998). Some aspects of students' problem solving difficulties in secondary school mathematics. Multi-disciplinary Journal of Education, 2 (2), 1-9.

Galadima, I \& Yushua'u, M. A. (2007). An investigation into mathematics performance of senior secondary school students in Sokoto state. Journal of Mathematical Association of Nigeria, 32 (1), 24-33.

Lassa, P.N. (2012). The teaching of mathematics for Nigerian secondary schools. Jos: Fab Anieh Nigeria Limited.

Moses, D. M. (2004). Gender differential in mathematics achievement in unity schools in Plateau state. Unpublished M.Ed Thesis, University of Jos.

Muscio, C. (1993). Challenging gender bias in fifth-grade. Educational leadership, 12 (1), 54-57.

Novak, J. D. \& Gowin, B. D. (1984). Learning how to learn. New York: Cambridge University Press.

Okebukola, P. A. (1999). An examination of the potency of the concept mapping technique. Journal of Research in Science Teaching, 25 (5), 85-92.

Penick, J. E. \& Alan, C. (1995). The power of cooperative learning. Research on Teaching and Learning, 2 (1), 22-24.

Slavin, R. E. (1987). What research says to the teacher; cooperative learning: Students team. Washington: National Education Association.

Totten, S., Sills, T. \& Russ, P. (1991). Cooperative learning: A guide to research. New York: Gerland Pub.

Ukeje, B. O. (1997). The challenges of mathematics in Nigeria economic goals of vision 2010: Implication for secondary school mathematics. A lead paper presented at the $34^{\text {th }}$ Annual National Conference of the Mathematical Association of Nigeria (MAN) held at Abuja from $1^{\text {st }} 66^{\text {th }}$, Sept.

West African Examinations Council, $(2008,2009)$. Chief examiner's report. Yaba: Lagos. 